\title{
Influência do grau de saturação no módulo de elasticidade dos solos: aplicação à previsão do alcance em quedas de blocos de rochas
}

\author{
The influence of saturation degree on soil elasticity \\ modulus: application on prediction the reach of rockfalls
}

\author{
Aliane Silva de Castro, Rafael Silva Ribeiro',2, Emilio Velloso Barroso, \\ Eurípedes do Amaral Vargas Júnior ${ }^{1,3}$, Helena Polivanov ${ }^{1}$ \\ 'Laboratório de Experimentos em Mecânica e Tecnologia de Rochas (LEMETRO), Programa de Pós-graduação em Geologia, \\ Departamento de Geologia, Universidade Federal do Rio de Janeiro - UFRJ, Avenida Athos da Silveira Ramos, 274, bloco J, sala J0-04 \\ - Campus Ilha do Fundão, Cidade Universitária, CEP 21941-916, Rio de Janeiro, RJ, BR (alianesdecastro@gmail.com; emilio@geologia. \\ ufr..br; hpolivanov@gmail.com) \\ 22Serviço Geológico do Brasil (CPRM), Rio de Janeiro, RJ, BR (rafasilrib@gmail.com) \\ ${ }^{3}$ Departamento de Engenharia Civil, Pontifícia Universidade Católica do Rio de Janeiro - PUC-Rio, Rio de Janeiro, RJ, BR (vargas@puc-rio.br)
}

Recebido em 04 de maio de 2016; aceito em 21 de novembro de 2017

\begin{abstract}
Resumo
O processo de queda de blocos rochosos é um dos mais destrutivos movimentos de massa em encostas. Considerando a baixa previsibilidade da sua deflagração, tem sido dada atenção à determinação das trajetórias dos blocos como método para redução de riscos. O coeficiente de restituição $(\varepsilon)$ é o principal parâmetro físico envolvido na análise do alcance dos blocos, pois representa as perdas de energia após os choques do bloco de rocha com diferentes materiais geológicos em sua trajetória. Trata-se de um parâmetro ainda pouco conhecido na literatura geológica e geotécnica, sobretudo quando se considera a interação dos blocos de rocha com solos em diferentes umidades. Este artigo teve a finalidade de avaliar o efeito da umidade do solo sobre o módulo de elasticidade (E), parâmetro elástico que afeta a rigidez no contato entre rocha e solo no momento do choque e, por conseguinte, o próprio $\varepsilon$. Para fins de comparação, um solo derivado de rocha ácida e outro de rocha básica foram coletados na região serrana do Estado do Rio de Janeiro. Procedeu-se à caracterização da mineralogia das rochas de origem e dos solos derivados, bem como dos índices físicos dos solos. Após a determinação da curva característica, os solos foram moldados em diferentes teores de umidade e submetidos a ensaios de compressão triaxial do tipo não adensado e não drenado. Os resultados mostraram variação de mais de uma ordem de grandeza do (E) em função da umidade do solo, indicando que esta tem considerável influência na rigidez do contato entre o solo e a rocha, tornando os alcances dependentes da variação sazonal de umidade nas encostas.
\end{abstract}

Palavras-chave: Módulo de Elasticidade; Umidade do Solo; Rigidez nos Contatos.

\begin{abstract}
Rock falls are one of the most destructive mass movements in hillslopes. Considering the low predictability of its triggering, attention has been paid in determining the paths of the blocks as a method to reduce risks. The coefficient of restitution $(\varepsilon)$ is the primary physical parameter involved in the analysis of the reach of the blocks. It represents the loss of energy after each shock of a rock block with different geological materials in its trajectory and it is still little known in geological and geotechnical literature, especially when considering the interaction of rock blocks with soil at different humidities. This article aimed to evaluate the effect of soil moisture on the elasticity modulus, an elastic parameter that affects the stiffness at the contact between rock and soil at the time of shock and, therefore, the actual coefficient of restitution. For comparison purposes, soils derived from acid rock and from basic rocks were sampled in the mountainous region of the State state of Rio de Janeiro. The procedure was to characterize the mineralogy of source rocks and its derived soils, as well as the physical indices of the soils. After determining the characteristic curve, the soils were molded at different moisture contents and subjected to unconsolidated and undrained triaxial compression tests. The results showed variation of elasticity modulus in more than an order of magnitude depending on the soil moisture, indicating that moisture has considerable influence on the stiffness of the contact between soil and rock during shocks, making the length of trajectories dependent of the seasonal variation of moisture in hillslopes.
\end{abstract}

Keywords: Elasticity Modulus; Soil Humidity; Contact Stiffness. 


\section{INTRODUÇÃO}

Entre os movimentos gravitacionais de massa em encostas, a queda e o rolamento de fragmentos de rocha de dimensões variando entre matacões e blocos (ABNT, 1995) ainda são processos pouco estudados e compreendidos, se comparados aos demais mecanismos de rupturas de encostas. Dados da última década (Vargas Jr. et al., 2004) e mais recentes (Lazaretti et al., 2015) demonstram que essa tipologia de movimento de massa tem se tornado cada vez mais frequente na cidade do Rio de Janeiro e no Estado do Espírito Santo, configurando áreas de risco e gerando prejuízos sociais e econômicos. Esse não é um problema circunscrito aos locais citados, mas tem vasta distribuição no território brasileiro e em outros países, além de ocorrer em diferentes contextos geológicos.

Tal tipo de movimento de massa apresenta algumas características singulares. A primeira delas refere-se à ausência de sinais premonitórios, o que dificulta a previsão do início do movimento. Vale ressaltar, inclusive, os registros de eventos dessa tipologia em períodos secos (Vargas Jr. et al., 2013). Outro aspecto relevante está relacionado com a altíssima velocidade do processo (Varnes, 1978), o que torna difícil a adoção de medidas mitigadoras após o início do movimento. Considerando essas características, a escolha de medidas estruturais e não estruturais eficientes para a proteção da população, bem como de equipamentos urbanos e elementos de infraestrutura, depende do conhecimento sobre as possíveis trajetórias e o alcance percorrido pelos matacões e blocos de rocha. Para a determinação do alcance e das trajetórias, é necessário conhecer o coeficiente de restituição $(\varepsilon)$, parâmetro relacionado à perda de energia em razão dos choques sucessivos entre a rocha e os materiais geológicos em sua trajetória.

Embora já existam dados na literatura sobre o $\varepsilon$, principalmente nos choques de rochas com superfícies também formadas por rochas, ainda há carência de dados quando se trata do $\varepsilon$ relativo aos choques entre os matacões e blocos de rocha e a superfície do talude formada por solo. Talvez esse fato seja explicado pelo amortecimento (baixo $\varepsilon$ ) produzido pelos solos, tornando-os menos críticos para o alcance dos matacões e blocos de rocha. Por outro lado, conforme já mencionado, a ocorrência dessa tipologia de movimento de massa parece não ter relação direta com períodos de elevada precipitação pluviométrica, havendo diversos registros de eventos em períodos secos. Tendo em vista que as propriedades mecânicas de solos são influenciadas pelo teor de umidade e que este varia sazonalmente, o presente trabalho teve como objetivo determinar o efeito da umidade no módulo de elasticidade (E) de solos e contribuir para a avaliação de como esse parâmetro pode afetar a rigidez no contato entre blocos e superfícies de solo nas encostas e, por conseguinte, o $\varepsilon$ entre ambos.

\section{CONHECIMENTO DO PROBLEMA}

Os movimentos gravitacionais de massa correspondem aos mecanismos de transporte de sedimentos, solos e rochas em encostas ou taludes, governados pela força gravitacional. Na natureza existem diferentes tipos de movimentos de massa envolvendo materiais, processos e fatores condicionantes variados. Uma das classificações de movimento de massa de maior relevância e que tem sido possível de ser aplicada no contexto regional brasileiro é a definida por Cruden e Varnes (1996), baseada na proposta de Varnes (1978), cujo critério de identificação dos movimentos gravitacionais de massa está baseado no material envolvido (solo, detritos ou rocha) que acompanha o movimento (queda, tombamento, deslizamento, escoamento e corridas).

Segundo Yilmas et al. (2008), a queda/rolamento de matacões e blocos de rocha é o movimento de massa em que um ou mais blocos desconexos do maciço rochoso caem ao longo de um declive por queda livre, saltação ou rolamento. No caso de movimentos com mais de um bloco envolvido, ao longo de toda a trajetória a interação principal ocorre entre estes e a superfície do terreno, sendo desprezível a interação entre os blocos de rocha (Hungr et al., 2014). Por simplicidade, a seguir faremos referência apenas aos blocos, embora reconheçamos que fragmentos de rocha com as dimensões de matacão também podem estar envolvidos no processo.

Esse é um evento de difícil previsão (Yilmas et al., 2008), uma vez que raramente emite algum sinal premonitório (Carnevale, 1991), e vem se tornando mais comum. No Brasil, eventos de queda de blocos têm se tornado mais frequentes, principalmente nas grandes cidades. Dados da Fundação Instituto de Geotécnica (Geo-Rio) atestam esse fato para o município do Rio de Janeiro há mais de uma década (Vargas et al., 2004). Levantamento recente do Serviço Geológico do Brasil mostra que essa tipologia de movimento de massa está relacionada com cerca de $16 \%$ das áreas de risco alto e muito alto no Estado do Espírito Santo, totalizando 59 municípios estudados ou aproximadamente $76 \%$ do território estadual (Lazaretti et al., 2015). Uma das ocorrências mais divulgadas pelos canais de imprensa teve lugar em Vila Velha, Espírito Santo, em janeiro de 2016, onde um bloco rolou, atingindo várias casas e ferindo, pelo menos, 10 pessoas. Esses dados revelam a importância de melhor se compreender os processos relacionados a essa tipologia de movimento em encostas, desde os mecanismos de deflagração até a movimentação propriamente dita.

A baixa previsibilidade do início do movimento está relacionada com as incertezas associadas aos possíveis mecanismos de deflagração da queda de blocos. Vargas et al. (2013) mostram que muitos dos eventos de queda de blocos na cidade do Rio de Janeiro ocorreram em períodos de ausência ou de baixíssima precipitação pluviométrica. 
Os autores mostraram, por meio de um programa experimental desenvolvido para medir as temperaturas na superfície dos taludes e também no seu interior, além de simulações numéricas nas quais foram utilizados dados de temperatura obtidos experimentalmente, que flutuações diárias de temperatura são capazes de levar à propagação de fraturas preexistentes nos taludes e, assim, promover a sua ruptura, bem como as quedas de blocos.

A movimentação dos blocos de rocha ao longo da encosta geralmente é modelada fazendo-se uso das equações de balística (Stevens, 1998; Ribeiro et al., 2008). As simulações numéricas têm como objetivo fundamental a determinação da trajetória e do alcance dos blocos, podendo ser uma importante ferramenta para análises de suscetibilidade e de risco em eventos relacionados a essa tipologia de movimento de massa. Entre os diversos parâmetros físicos envolvidos na análise dos movimentos de blocos (massa do bloco, velocidade inicial horizontal, velocidade inicial vertical, velocidade angular e ângulo de atrito), o $\varepsilon$ talvez seja o mais importante e difícil de ser obtido (Stevens, 1998). Tal coeficiente, definido pela razão entre as velocidades após $\left(v_{\mathrm{n}+1}\right)$ e antes $\left(v_{\mathrm{n}}\right)$ do impacto (Equação 1), corresponde à energia cinética dissipada em sucessivos impactos entre sólidos; essas colisões podem ser classificadas pela capacidade de conservação de energia cinética no choque.

$\varepsilon=\frac{v_{n+1}}{v_{n}}$

Diferentes técnicas para determinação experimental do $\varepsilon$ têm sido apresentadas na literatura. Rayudu (1997), Peng (2000), Chau et al. (2002), Heidenreich (2004) e Machado (2013) determinaram os valores do $\varepsilon$, em laboratório, com o auxílio de uma câmera de alta velocidade para a definição da posição de esferas de diferentes materiais (aço, gesso dental, rochas etc.) após os choques com superfícies inclinadas e, assim, calcular os coeficientes de restituição normal e tangencial à superfície. Ainda dentro do laboratório, Dias e Barroso (2006) determinaram o $\varepsilon$ normal de um gnaisse por intermédio do registro sonoro de sucessivos impactos de uma esfera rochosa em uma superfície horizontal, de acordo com método acústico proposto por Bernstein (1977). Testes in situ foram executados por Giani et al. (2004), em que blocos de rocha foram lançados do topo da encosta no Apeninos (Itália) e câmeras posicionadas ao longo do percurso gravaram a trajetória do bloco. A partir da análise das imagens, parâmetros como velocidade, ângulo de rotação dos blocos e os coeficientes de restituição foram definidos.

Durante a realização de uma série de testes in situ, Ritchie (1963) afirmou que a inclinação da encosta e suas irregularidades determinam a cinemática dos blocos. Esse autor observou que a perda de energia se torna maior com o aumento da rugosidade da superfície da encosta, com a elevação do comportamento plástico da superfície, principalmente se for composta por solo não compacto, e com o crescimento do ângulo de impacto. Barbieri et al. (1988) e Azzoni e Freitas (1995) estudaram a influência desses parâmetros sobre a trajetória dos blocos e sobre os coeficientes de restituição. Esses autores afirmaram que a velocidade de rotação, bem como o rebote dos blocos (e, portanto, sua energia cinética total), é menos distinta para encostas de detritos do que para os taludes rochosos; sendo assim, os coeficientes de restituição tendem a diminuir com a redução da dureza do material geológico na encosta.

Um dos parâmetros de grande influência sobre a perda de energia durante os choques, e, por conseguinte, diretamente relacionado com o $\varepsilon$, é a rigidez nos contatos entre os blocos em queda e a superfície da encosta. Tal característica entre dois materiais em choque pode ser descrita pela Teoria de Hertz, parte da mecânica do contato. Se a força de um corpo (indentador) é aplicada sobre outro corpo (espécime ou superfície indentada), há uma deformação e a formação de um raio de contato $a$ (área de contato), conforme ilustrado pela Figura 1. No caso das encostas, o corpo indentador é representado pelo bloco de rocha em movimentação e a superfície da encosta caracteriza o corpo indentado.

Essa área do contato é diretamente dependente das propriedades elásticas e mecânicas, tanto do indentador como da superfície indentada. Segundo Pulecio (2010), a rigidez normal $\left(k_{\mathrm{n}}\right)$ de um corpo é a capacidade de resistir à deformação quando uma força é aplicada, podendo ser definida segundo a variação de deslocamento $(d \delta)$ produzida em razão da aplicação de força $(d \vec{P})$, conforme a Equação 2:

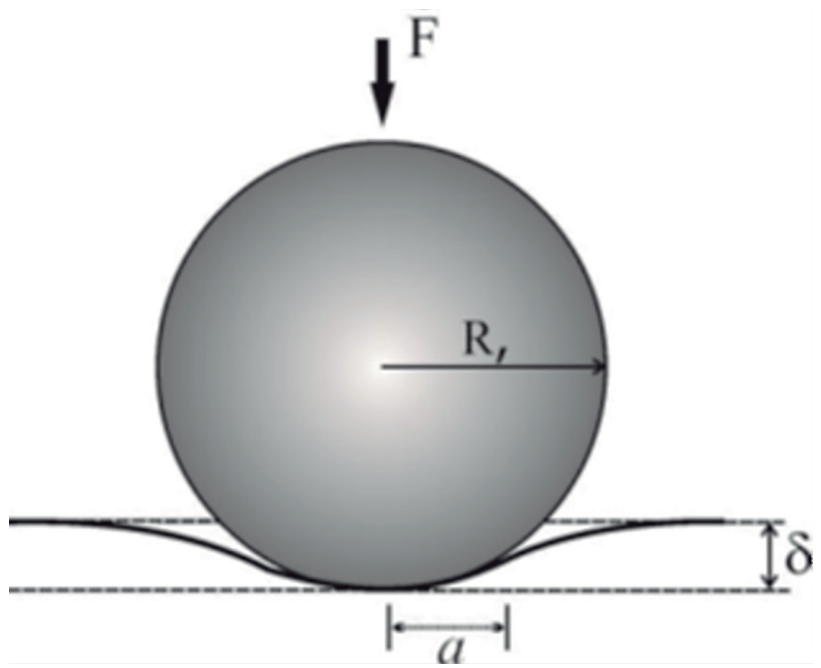

Figura 1. Desenho representativo de uma indentação. A esfera representa o corpo indentador, onde uma força ao ser aplicada na superfície indentada provoca uma deformação, logo, a formação de um raio de contato (Ribeiro, 2013). 
$k_{n}=\frac{d \vec{P}}{d \delta}$

Derivando-se a carga em relação à profundidade de indentação, obtém-se a Equação 3:

$k_{n}=\frac{2}{\sqrt{\pi}} E^{*} \sqrt{\pi a^{2}}$

Em que E* é a combinação dos módulos do indentador (bloco de rocha) e da superfície indentada, dada pela Equação 4:

$\frac{1}{E^{*}}=\frac{\left(1-v^{2}\right)}{E}+\frac{\left(1-v^{\prime 2}\right)}{E^{\prime}}$

Em que $E$ ' é o módulo de elasticidade do indentador (bloco de rocha); $v^{\prime}$, o coeficiente de Poisson do indentador (bloco de rocha); $E$, o módulo de elasticidade da superfície indentada (material na superfície da encosta); e $v$, o coeficiente de Poisson da superfície indentada (material na superfície da encosta). Conforme se observa, o (E) dos corpos é um parâmetro-chave para o cálculo da rigidez normal. $O \varepsilon$ será tanto mais elevado quanto maior for a rigidez no contato do bloco de rocha com o material presente na encosta (rocha, solo, colúvio ou tálus).

\section{ÁREAS DE ESTUDOS}

As áreas nas quais os materiais foram retirados para a realização do presente trabalho estão localizadas nos municípios de Petrópolis e Sumidouro, região serrana do Estado do Rio de Janeiro. A escolha desses locais se fez principalmente pelo fato de essa região apresentar um histórico de eventos de instabilidade de encostas, com várias ocorrências, como a tragédia ocorrida em janeiro de 2011.

\section{Petrópolis}

A área de estudo está situada no Bairro da Glória, Distrito de Cascatinha, cujos limites estão dentro da Área de Proteção Ambiental da Região Serrana de Petrópolis (APA Petrópolis). A geologia local é caracterizada por afloramentos rochosos de hornblenda-biotita gnaisse, encontrados, muitas vezes, encobertos por solo residual. Esses gnaisses de idade neoproterozoica correspondem à unidade denominada Batólito Serra dos Órgãos, pertencente ao Complexo Rio Negro (Tupinambá, 1999). Ainda no local se encontra uma grande área em que há inúmeros matacões e blocos rochosos, cujos diâmetros variam de poucos centímetros a uma dezena de metros, correspondendo a um depósito de tálus associado a um colúvio. Com relação à geomorfologia, o relevo acentuado é marcante. Nesse local há uma porção mais elevada e escarpada, na base da qual se situam matacões e blocos de dimensões variadas, além de morros com cumes arredondados e vales marcantes, em que está localizada a maior parte das construções.

\section{Sumidouro}

Essa área estudada está situada no pequeno povoado de Murineli, que pertence ao distrito sede de Sumidouro. A geologia local é caracterizada pela presença de rochas do Complexo Rio Negro, redefinida por Tupinambá et al. (1996) como um conjunto ortoderivado representante de um arco magmático (Complexo Rio Negro) constituído por ortognaisses e granitoides (diorito, tonalito gnaisse, leucogranito e gnaisse porfiroide) fracamente deformados e com diversas feições de injeção entre si, sendo difícil a determinação do tipo predominante. Além dessas unidades, ocorre a Suíte Cordeiro, formada por gnaisse leucocrático a hololeucocrático de cor esbranquiçada a cinza-clara de granulação média a grossa, mais ao sul está a Suíte Serra dos Órgãos, formada por gnaisses (Tupinambá et al., 2012). Há a presença também de enxames de diques da Serra do Mar, enxame de diques de Paquequer Pequeno-Sumidouro, compostos por diabásio ou microgabro, de textura equigranular com apatita, rutilo e minerais opacos magnéticos como acessórios, clinopiroxênio alterando para hornblenda e a biotita e o plagioclásio encontram-se parcialmente sericitizados. A geomorfologia local apresenta os domínios de morros elevados (com ocorrência de "Pães-de-Açúcar"), relevo de morros convexo-côncavos dissecados e topos arredondados ou aguçados, constituídos por depósitos de colúvios, alúvios e, subordinadamente, tálus.

\section{MÉTODOS}

A fim de determinar e investigar os tipos de materiais geológicos usados no estudo, bem como individualizar suas características, as seguintes análises foram executadas: petrografia, com descrições macroscópicas e microscópicas e caracterização física, para a correta definição dos tipos de rocha; ensaios de caracterização física e mineralógica dos tipos de solos; ensaios para determinação da curva característica (técnica do papel-filtro); e ensaios de compressão triaxial dos solos.

\section{Petrografia}

As amostras foram coletadas em campo, diretamente nos blocos presentes nas encostas. Depois de cortadas, uma fatia 
de cada rocha foi colada em lâmina de vidro e desbastada até a espessura padrão de $0,03 \mathrm{~mm}$. As lâminas petrográficas foram analisadas com a técnica da luz transmitida para a definição da mineralogia e textura das rochas, seus aspectos de alteração intempérica e classificação do tipo litológico.

\section{Massa específica e porosidade da rocha}

A caracterização física da rocha foi realizada com base nos ensaios para a determinação da porosidade e da massa específica aparente, executados conforme prescrição da Norma Brasileira (NBR) 12766 (ABNT, 1992). Essa análise foi realizada de forma a complementar as informações da petrografia para definição do grau de alteração das rochas. Dados sobre a porosidade também são relevantes, pois afetam diretamente os parâmetros elásticos das rochas e, como consequência, a rigidez normal no contato, conforme evidenciam as Equações 3 e 4.

\section{Curvas granulométricas e limites de Atterberg}

Os ensaios de caracterização física dos solos foram realizados com as amostras amolgadas, coletadas e preparadas de acordo com a NBR 6457 (ABNT, 1986). Dessa amostra foram realizados os ensaios de limite de liquidez pela NBR 6459 (ABNT, 1984c), limite de plasticidade pela NBR 7180 (ABNT, 1984d), massa específica dos grãos pela NBR 6508 (ABNT, 1984a) e análise granulométrica pela NBR 7181 (ABNT, 1984b). Essa caracterização é útil para a classificação dos solos no Sistema Unificado de Classificação de Solos (SUCS) e para auxiliar na compreensão do seu comportamento mecânico.

\section{Mineralogia por difração de raios-X}

Comumente, a classificação e a identificação dos grupos de argilominerais podem ser obtidas por meio da difração de raios-X. O procedimento teve início com a separação da fração argila a partir de uma solução com defloculante e com as partículas da fração fina do solo em suspensão. O método empregado se baseia na metodologia preconizada por Jackson (1958), com modificações de Polivanov (1998), com a confecção de lâminas orientadas nas seguintes condições: naturais, saturadas a vácuo em atmosfera de etilenoglicol e aquecidas em forno mufla a temperatura de $550^{\circ} \mathrm{C}$. A mineralogia da fração argila é fundamental para se entender o comportamento do solo, principalmente quando úmido, pois aspectos como a plasticidade e a atividade são dependentes da porcentagem de argila e também do tipo de argilomineral presente no solo. Características como a capacidade de troca catiônica e a adsorção de água dependem do tipo do argilomineral. A habilidade de retenção de água, por sua vez, afeta o (E) dos solos, os quais se apresentam mais rígidos e com baixos teores de umidade.

\section{Curvas de retenção de água}

Para a obtenção da curva característica, foi usada a metodologia descrita na norma D 5298 (ASTM, 2003a). A técnica consiste em colocar um papel-filtro em contato direto com a amostra de solo até que ocorra um equilíbrio de sucção, por meio do fluxo capilar entre o papel e a amostra. O objetivo da determinação das curvas de retenção de água (CRA) foi estabelecer as relações entre a umidade do solo ou grau de saturação e a sucção mátrica que se desenvolve no seu interior.

\section{Ensaios de compressão triaxial}

E, por fim, o ensaio triaxial realizado foi do tipo UU (Unconsolidated Undrainded), descrito na norma D 2850 (ASTM, 2003b). Para a realização, foram aplicadas pressões confinantes de $20 \mathrm{kPa}$ e impostas velocidades de deslocamento axial de $1 \mathrm{~mm} / \mathrm{min}$. durante a fase de cisalhamento. O objetivo do experimento foi simular a condição de carregamento instantâneo que ocorre no impacto dos blocos de rocha com o solo superficial, por isso a alta velocidade de carregamento e a baixa tensão confinante. Os ensaios foram realizados no Laboratório de Geotecnia e Meio Ambiente (LGMA) da Pontifícia Universidade Católica do Rio de Janeiro (PUC-Rio).

\section{RESULTADOS E DISCUSSÕES}

\section{Petrografia}

A rocha da área de Petrópolis (Figura 2A) se caracteriza macroscopicamente como uma leucocrática de cor cinzaclara, levemente esverdeada, e de granulação média. O tipo de alteração na rocha é intempérica de intensidade baixa. Apresenta uma textura nematogranoblástica e estruturalmente possui um bandamento gnáissico pouco nítido. Os minerais identificados foram plagioclásio, quartzo, biotita e anfibólio (hornblenda). Já a rocha da área de Sumidouro (Figura 2B) foi caracterizada como fanerítica, holocristalina, mesocrátrica, de cor cinza-escura, inequigranular, de granulação fina a média, e apresenta capa alteração nas bordas dos matacões e blocos de rocha. Os minerais identificados foram plagioclásio, piroxênio e opacos. Os plagioclásios possuem granulação média predominante, enquanto os demais são finos, menores que $1 \mathrm{~mm}$.

Com a análise das lâminas petrográficas no microscópio, as rochas foram classificadas como um hornblenda-biotita gnaisse e um gabro: o hornblenda-biotita gnaisse de granulação média e coloração acinzentada é composto predominantemente por plagioclásio e quartzo, perfazendo cerca de 
$70 \%$ da constituição da rocha, além de biotita, K-Na feldspato e anfibólio (Figura 3A). O gabro, de granulação média e cor acinzentada, contém cerca de $50 \%$ de plagioclásios, além de piroxênio, clorita, biotita e saussurita (Figura 3B). As lâminas petrográficas mostraram a baixa intensidade da alteração de ambas as rochas por intemperismo, confirmando as observações macroscópicas.

\section{Massa específica e porosidade da rocha}

Na Tabela 1 encontra-se o hornblenda-biotita gnaisse, que possui porosidade média de $1,73 \%$ e massa específica seca média de $2,63 \mathrm{~g} / \mathrm{cm}^{3}$. O gabro possui uma porosidade média de $1,74 \%$ e massa específica seca média de $2,90 \mathrm{~g} / \mathrm{cm}^{3}$ (Tabela 2). Os valores de porosidade indicam que ambas as rochas estão apenas levemente alteradas, visto que são esperados valores de porosidade inferiores a $1 \%$. Os dados físicos corroboram as observações mineralógicas, tanto macroscópicas quanto microscópicas, com relação à intensidade de alteração das rochas. Os maiores valores de massa específica aparente seca para os gabros estão de acordo com o caráter máfico dessa rocha.

\section{Curvas granulométricas e limites de Atterberg}

O ensaio de granulometria resultou nas curvas apresentadas na Figura 4. O solo derivado do hornblenda-biotita gnaisse apresentou uma porcentagem alta de argila (48\%), enquanto o solo derivado do gabro mostrou uma porcentagem maior de areia na sua composição (66\%). Na Tabela 3 são apresentadas as composições granulométricas de ambos os solos, assim

Tabela 1. Valores de porosidade e massa específica seca do hornblenda-biotita gnaisse.

\begin{tabular}{lcc}
\hline \multicolumn{3}{l}{ Hornblenda-biotita gnaisse } \\
\hline Amostra & $\mathbf{n}(\%)$ & $\rho_{\mathrm{d}}\left(\mathbf{g} / \mathrm{cm}^{3}\right)$ \\
\hline 1 & 1,16 & 2,71 \\
2 & 1,37 & 2,63 \\
3 & 2,73 & 2,59 \\
4 & 1,75 & 2,62 \\
5 & 1,56 & 2,63 \\
6 & 1,72 & 2,63 \\
7 & 1,78 & 2,62 \\
Média & 1,73 & 2,63
\end{tabular}

$\mathrm{n}$ : valores de porosidade; $\rho_{\mathrm{d}}$ : massa específica seca.
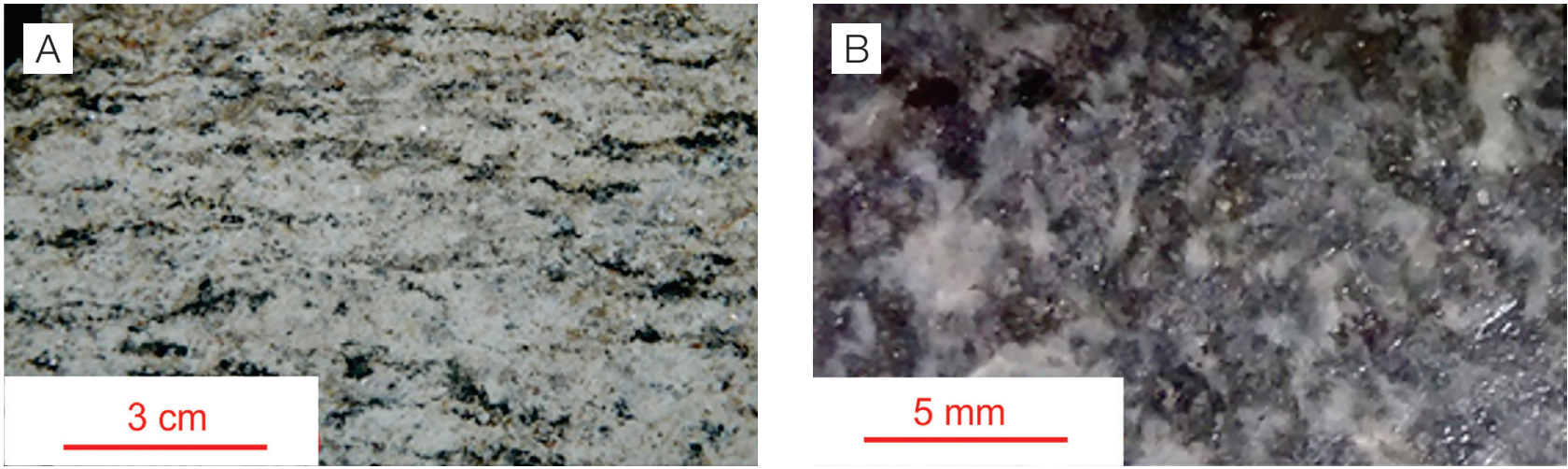

Figura 2. (A) Rocha da área de Petrópolis; (B) rocha da área de Sumidouro.
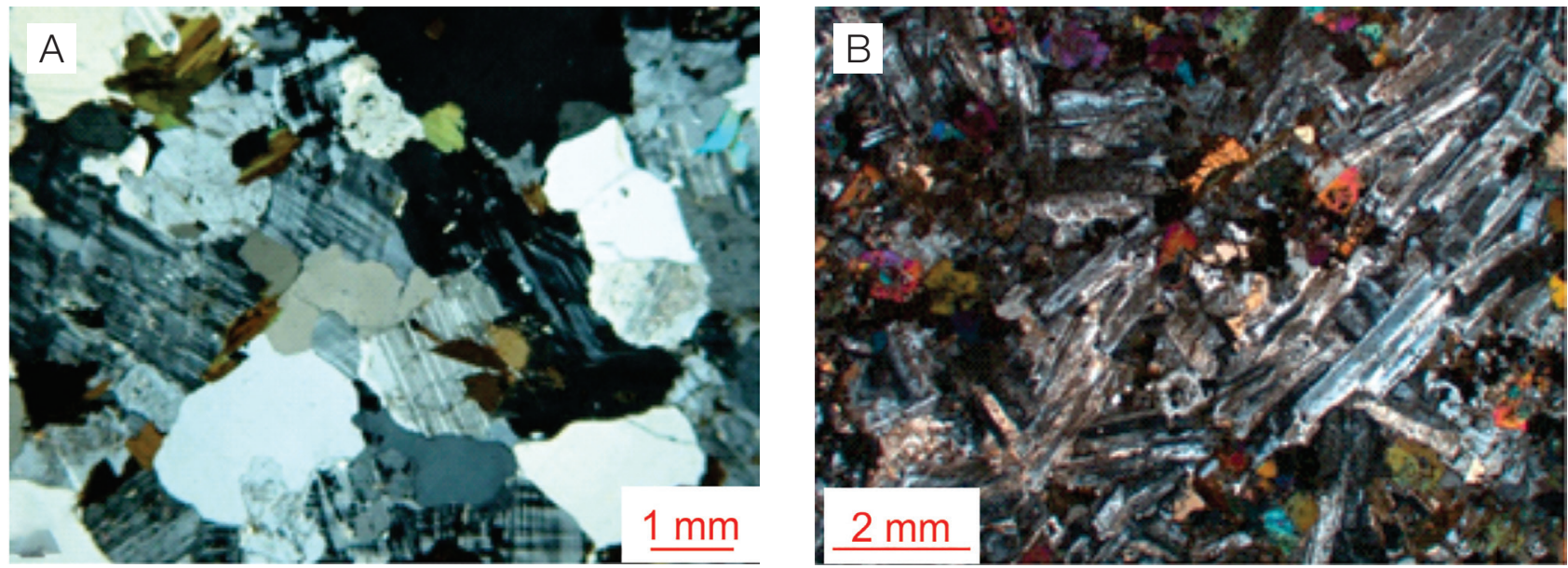

Figura 3. (A) Lâmina petrográfica do hornblenda-biotita gnaisse; (B) lâmina petrográfica do gabro. 
como os valores do coeficiente de não uniformidade (CNU) e do coeficiente de curvatura (CC), além da classificação segundo o SUCS. O solo derivado do hornblenda-biotita

Tabela 2. Valores de porosidade e massa específica seca do gabro.

\begin{tabular}{lcc}
\hline Gabro & $\mathbf{n}(\%)$ & $\rho_{\mathbf{d}}\left(\mathbf{g} / \mathbf{c m}^{3}\right)$ \\
\hline Amostra & 2,04 & 2,88 \\
2 & 1,71 & 2,93 \\
3 & 1,63 & 2,87 \\
4 & 1,88 & 2,87 \\
5 & 1,36 & 2,95 \\
6 & 1,60 & 2,94 \\
7 & 2,40 & 2,86 \\
8 & 1,65 & 2,93 \\
9 & 0,97 & 2,93 \\
10 & 2,15 & 2,88 \\
Média & 1,74 & 2,90 \\
\hline
\end{tabular}

n: valores de porosidade; $\rho_{d}$ : massa específica seca. gnaisse corresponde a um $\mathrm{CH}$ (argila de alta plasticidade), e o solo derivado do gabro, a um SW-SM (areia bem graduada siltosa). $\mathrm{O}$ solo $\mathrm{CH}$ não apresenta valores de $\mathrm{CNU}$ e $\mathrm{CC}$, por não se tratar de um solo arenoso.

Os índices de atividade de Skempton, relativos às argilas presentes em ambos os solos, são baixos, respectivamente 0,46 para o solo derivado do ganisse $(\mathrm{CH})$ e 0,38 para o solo derivado do gabro (SW-SM). Esses valores caracterizam as argilas presentes em ambos os solos como inativas.

A Tabela 4 apresenta um resumo dos índices físicos dos solos, como os valores de peso específico real dos grãos $\left(\rho_{\mathrm{s}}\right)$, teor de umidade (w), grau de saturação (S), porosidade (n) e índice de vazios (e), limites de consistência (LL - limite de liquidez; LP - limite de plasticidade; e IP - índice de plasticidade) e índice de atividade de Skempton (Ia).

\section{Mineralogia por difração de raios-X}

Os difratogramas de raios- $\mathrm{X}$ acusaram a presença predominante de caulinita, seguida por gibsita e traços de ilita no

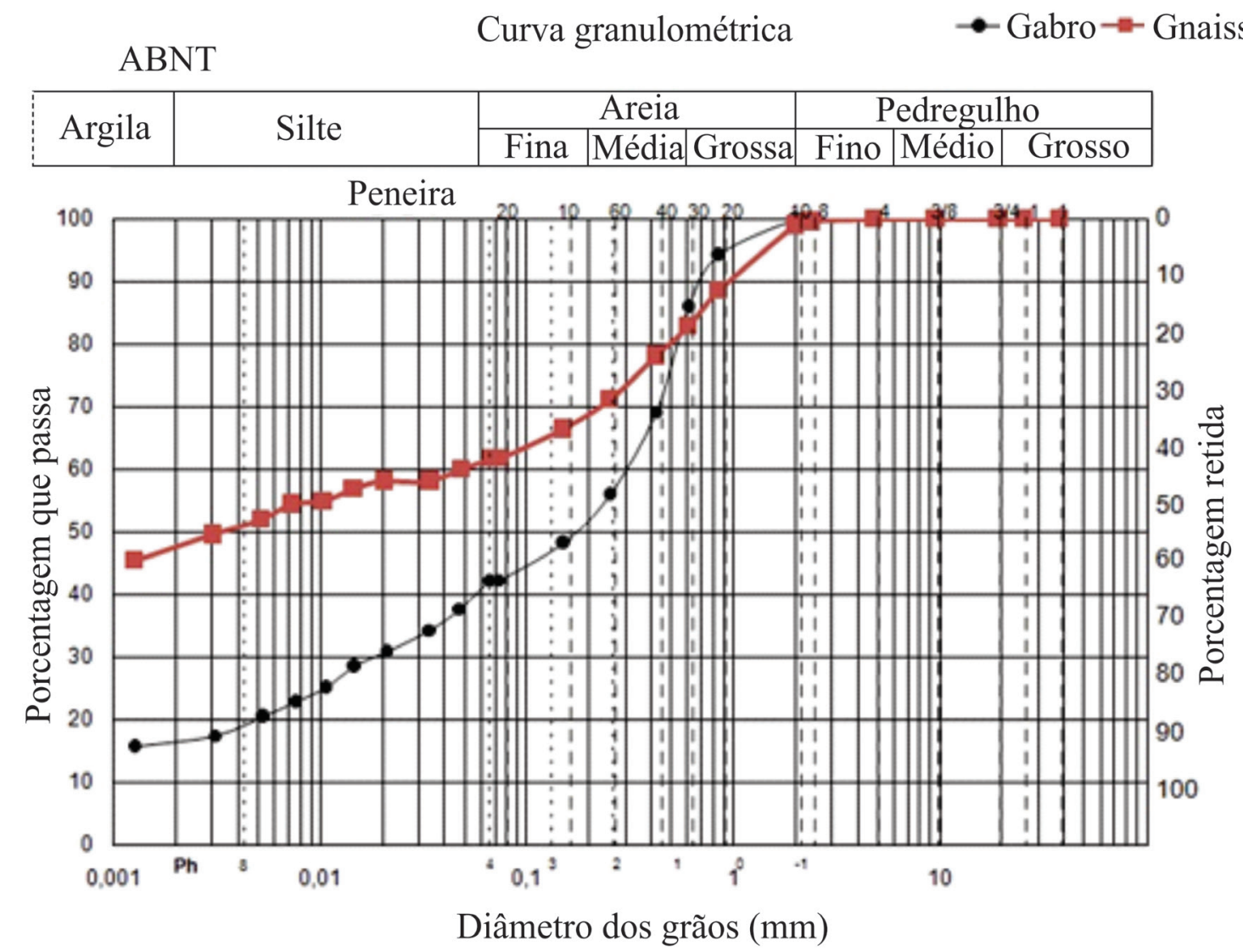

Figura 4. Curvas granulométricas dos solos. A curva em vermelho refere-se ao solo proveniente do hornblenda-biotita gnaisse, e a em preto, ao solo do gabro. 
solo $\mathrm{CH}$, derivado do hornblenda-biotita gnaisse. No solo SW-SM, derivado do gabro, foram encontrados caulinita, gibsita e traços de goethita na fração argila (Tabela 5).

Os dados mineralógicos da fração argila dos solos corroboram os índices físicos obtidos. A mineralogia obtida por difração de raios-X (DRX) é compatível com as argilas de baixa atividade, conforme previsto pelo índice de atividade de Skempton. A baixa atividade está relacionada com a composição mineralógica da fração argila, formada essencialmente por minerais com estrutura 1:1 e com baixa capacidade de adsorção de água. Portanto, a quantidade de argila e de argila mais silte (porcentagem de finos) deve ser a responsável pelo comportamento do solo adiante da água, incluindo suas propriedades elásticas, que afetam a rigidez no contato solo rocha durante os impactos, uma vez que as mineralogias da fração argila são semelhantes.

\section{Curvas de retenção de água}

Pelo método do papel-filtro foram obtidas as curvas características (Figuras 5 e 6) dos solos $\mathrm{CH}$ e SM, respectivamente. $\mathrm{Na}$ Figura 5, é possível classificar a curva como bimodal, pois ela possui dois valores de entrada de ar. O primeiro ocorre quando a sucção matricial é de $7 \mathrm{kPa}$ para a saturação de $89 \%$, e o segundo, quando a sucção alcança cerca de $3.000 \mathrm{kPa}$, correspondente ao grau de saturação de $67 \%$. Além disso, outra característica marcante da curva é a ocorrência do patamar intermediário existente entre os valores aproximados de 30 e $2.000 \mathrm{kPa}$.

A curva bimodal indica que o solo estudado possui um conjunto bem definido de macroporos e microporos, ou seja, contém distribuição de tamanho de poros não uniforme. É justamente nos dois valores de entrada de ar que ocorre a dessaturação dos macroporos e microporos.
Na Figura 6, a curva característica foi classificada como unimodal, com valor de entrada de ar a 3,5 kPa de sucção matricial para saturação a $82 \%$. Como é um solo arenoso siltoso, era esperado que a curva apresentasse um comportamento intermediário entre os solos arenosos e siltosos. A curva possui uma declividade suave, evidenciando uma dessaturação gradual. A curva unimodal indica que o solo possui um conjunto de poros característico de solos arenosos, mas como o solo estudado possui uma porcentagem significativa de silte (26\%), a dessaturação não se fez de forma brusca e rápida, salientando um diâmetro não muito grande desses poros, uma vez que os finos (silte) podem estar preenchendo os vazios entre os grãos maiores.

\section{Ensaios de compressão triaxial}

Os ensaios triaxiais de solo tiveram o objetivo de determinar como se dá o comportamento do (E) adiante da variação de suç̧ão e de umidade do solo. Tal módulo é indispensável no cálculo das equações de rigidez nos contatos. Os resultados dos ensaios triaxiais dos oito corpos-de-prova do solo $\mathrm{CH}$, exibidos na Figura 7, permitem afirmar que a umidade influi no comportamento da curva tensão efetiva $\left(\sigma^{\prime}\right)$ - deformação axial $(\varepsilon)$. Os corpos-de-prova mais secos, como esperado,

Tabela 5. Argilominerais presentes na fração argila dos solos derivados do ganisse (CH) e do gabro (SW-SM).

\begin{tabular}{lcc}
\hline Solos & Fração & Argilominerais \\
\hline $\mathrm{CH}$ & Argila & $\begin{array}{c}\text { Caulinita } \\
\text { Gibsita } \\
\text { Traços de llita }\end{array}$ \\
\hline SW-SM & Argila & $\begin{array}{c}\text { Caulinita } \\
\text { Gibsita } \\
\text { Traços de goethita }\end{array}$ \\
\hline
\end{tabular}

Tabela 3. Composição granulométrica, porcentagem em massa, dos solos, respectivos valores de coeficiente de não uniformidade e coeficiente de curvatura e classificação segundo o Sistema Unificado de Classificação de Solos.

\begin{tabular}{|c|c|c|c|c|c|c|c|c|}
\hline \multirow[b]{2}{*}{$\begin{array}{l}\text { Tipos } \\
\text { de solo }\end{array}$} & \multicolumn{5}{|c|}{ Granulometria (\%) } & \multirow[b]{2}{*}{$\mathrm{CNU}$} & \multirow[b]{2}{*}{$\mathrm{CC}$} & \multirow[b]{2}{*}{$\begin{array}{l}\text { Classificação } \\
\text { SUCS }\end{array}$} \\
\hline & Argila & Silte & Areia fina & $\begin{array}{l}\text { Areia } \\
\text { média }\end{array}$ & $\begin{array}{c}\text { Areia } \\
\text { grossa }\end{array}$ & & & \\
\hline Gnaisse & 48 & 14 & 07 & 14 & 17 & - & - & $\mathrm{CH}$ \\
\hline Gabro & 08 & 26 & 17 & 35 & 14 & 79 & 02 & SW-SM \\
\hline
\end{tabular}

CNU: coeficiente de não uniformidade; CC: coeficiente de curvatura; SUCS: Sistema Unificado de Classificação de Solos.

Tabela 4. Índices físicos, limites de consistência e índices de atividade de Skempton dos solos derivados do ganisse (CH) e do gabro (SW-SM).

\begin{tabular}{lccccccccc}
\hline \multirow{2}{*}{ Solos } & \multirow{2}{*}{$\mathbf{w}(\%)$} & \multirow{2}{*}{$\mathbf{S}(\%)$} & \multirow{2}{*}{$\rho_{\mathrm{d}}\left(\mathbf{g} / \mathbf{c m}^{3}\right)$} & $\mathrm{E}$ & $\mathrm{n}(\%)$ & \multicolumn{3}{c}{ Limites de consistência } & \multirow{2}{*}{ la } \\
\hline CH & 24,25 & 76,39 & 25,8 & 0,83 & 45,23 & 54 & 32 & 22 & 0,46 \\
SW-SM & 13,72 & 37,17 & 27,4 & 1,01 & 50,00 & 58 & 55 & 3 & 0,38 \\
\hline
\end{tabular}

W: teor de umidade; S: grau de saturação; $\rho_{d}$ : massa específica aparente seca; E: módulo de elasticidade; n: porosidade; LL: limite de liquidez; LP: limite de plasticidade; IP: índice de plasticidade; la: índice de atividade. 
apresentaram maior resistência adiante daqueles com maior teor de umidade. As curvas dos corpos-de-prova com mais baixa umidade chegaram, inclusive, a conter picos de resistência bem definidos, denotando comportamento frágil. Nos teores de umidade mais elevados, as curvas tensãodeformação passam a apresentar comportamento dúctil com endurecimento. Os resultados dos ensaios triaxiais

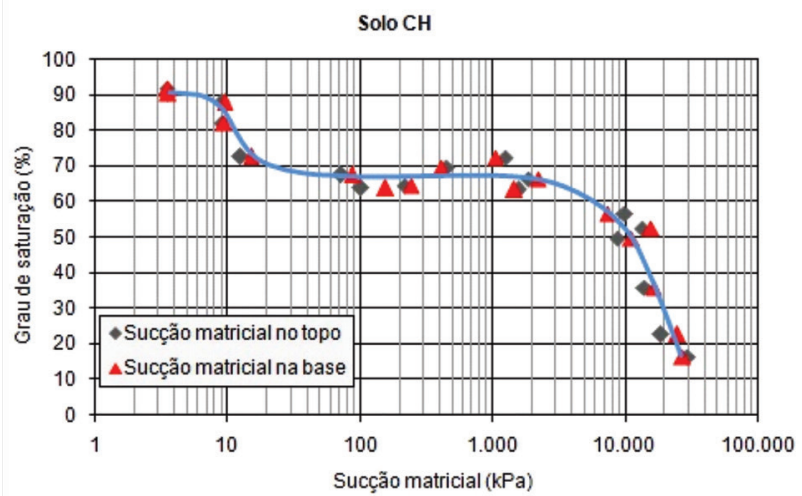

Figura 5. Curva característica bimodal do solo $\mathrm{CH}$.

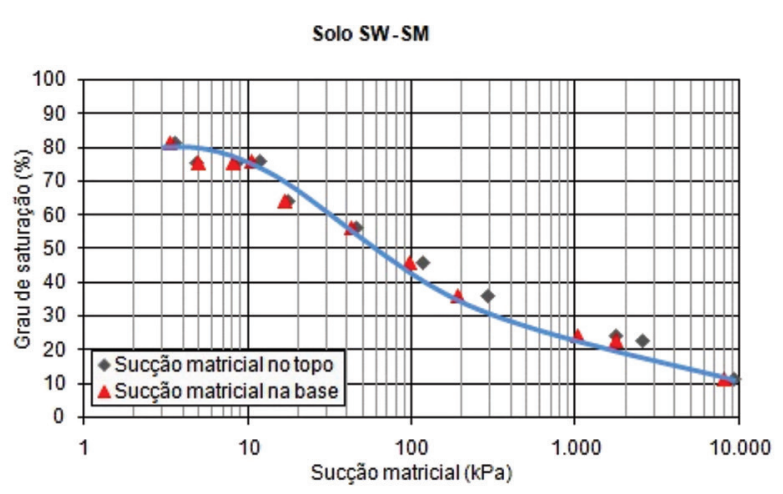

Figura 6. Curva característica unimodal do solo SW-SM.

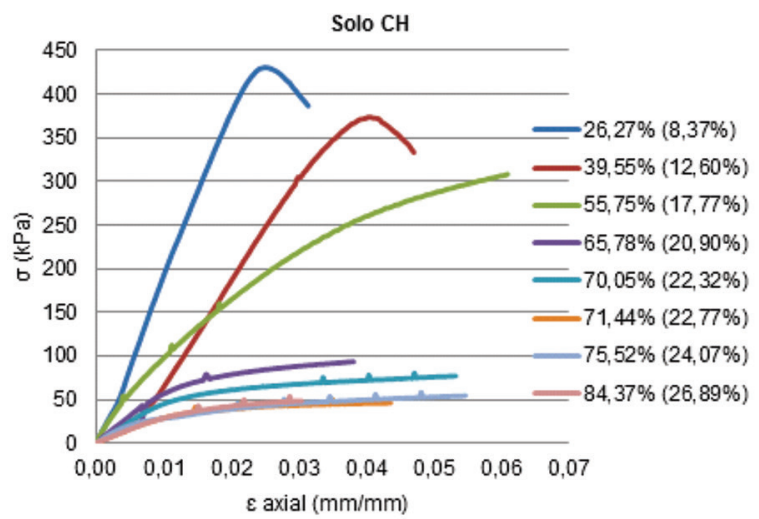

Figura 7. Resultados dos ensaios triaxiais do solo $\mathrm{CH}$, em função do grau de saturação. O teor de umidade aparece entre parênteses na legenda. dos cinco corpos-de-prova do solo SW-SM, exibidos na Figura 8, apresentam menor resistência do que os solos $\mathrm{CH}$, mas com curvas tensão-deformação axial com tendência geral de comportamento semelhante àquele observado para os solos $\mathrm{CH}$.

Em seguida, os módulos de elasticidade não drenados $\left(E_{u}\right)$ foram calculados, considerando-se as tangentes às curvas nos trechos retilíneos das curvas tensão-deformação. A Tabela 6 apresenta os módulos não drenados e as respectivas umidades dos solos.

Nas Figuras 9 e 10, os gráficos que relacionam o (E) não drenado com o grau de saturação mostram variações de uma ordem de grandeza desse parâmetro elástico em função do grau de saturação ou umidade do solo. O módulo não drenado variou significativamente, de $2.062 \mathrm{kPa}$ para o corpode-prova mais úmido a $19.173 \mathrm{kPa}$ para o mais seco, no solo CH. No solo SW-SM, observou-se que corpo de prova mais seco teve um (E) não drenado na faixa dos $19.000 \mathrm{kPa}$ com o grau de saturação em aproximadamente $26 \%$, e o corpo de prova mais úmido teve o seu (E) na faixa dos $1.800 \mathrm{kPa}$

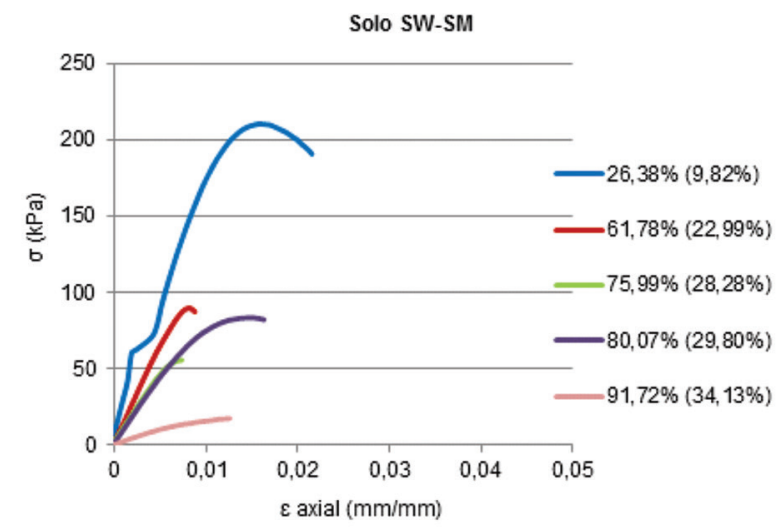

Figura 8. Resultados dos ensaios triaxiais do solo SWSM em função do grau de saturação. O teor de umidade aparece entre parênteses na legenda.

Tabela 6. Relação entre os módulos de elasticidade não drenados e as umidades dos solos derivados do ganisse $(\mathrm{CH})$ e do gabro (SW-SM).

\begin{tabular}{cccc}
\hline \multicolumn{2}{c}{ Solo $\mathbf{C H}$} & \multicolumn{2}{c}{ Solo SW-SM } \\
\hline $\mathbf{W}$ & $\begin{array}{c}\mathbf{E}_{\mathrm{u}} \\
\mathbf{( \% )}\end{array}$ & $\begin{array}{c}\mathbf{W} \\
\mathbf{( M P )}\end{array}$ & $\begin{array}{c}\mathbf{E}_{\mathrm{u}} \\
\mathbf{( M P a )}\end{array}$ \\
\hline 8,37 & 19,17 & 09,82 & 19,10 \\
12,60 & 10,28 & 22,99 & 12,60 \\
17,77 & 07,67 & 28,28 & 08,83 \\
20,90 & 05,59 & 29,80 & 08,12 \\
22,32 & 04,78 & 34,13 & 01,84 \\
22,77 & 03,08 & & \\
24,07 & 02,76 & & \\
26,89 & 02,06 & & \\
\hline
\end{tabular}


para $92 \%$ de umidade. Assim, constata-se que o (E) não drenado apresenta forte redução conforme o incremento da umidade ou do grau de saturação do solo.

As relações dos módulos de elasticidade não drenados dos solos com os graus de saturação (ou umidades) são claramente não lineares, como atestam as equações de ajustes apresentadas nos gráficos das Figuras 9 e 10. Assim, podese compreender que a rigidez normal no contato rocha-solo será diretamente afetada pela condição de umidade do solo.

Ao se examinar a Equação 3, é possível notar que a rigidez normal é influenciada por dois parâmetros: um geométrico "a", que é a área de contato entre a rocha e o solo, e $E^{*}$, que é a combinação dos parâmetros elásticos ( $\mathrm{E}$ e $\left.v\right)$ dos corpos envolvidos no choque e é determinado em função da Equação 4. Em outras palavras, empregando-se as Equações 3 e 4 deste artigo é possível verificar a relação entre a rigidez normal dos solos na condição seca e na condição úmida.

Para o cálculo de $\mathrm{E}^{*}$, empregam-se os valores de $\mathrm{E}_{u}$ e $v$ do solo e E' e $v^{\prime}$ da rocha. A variação de $\mathrm{E}_{\mathrm{u}}$ com o grau de

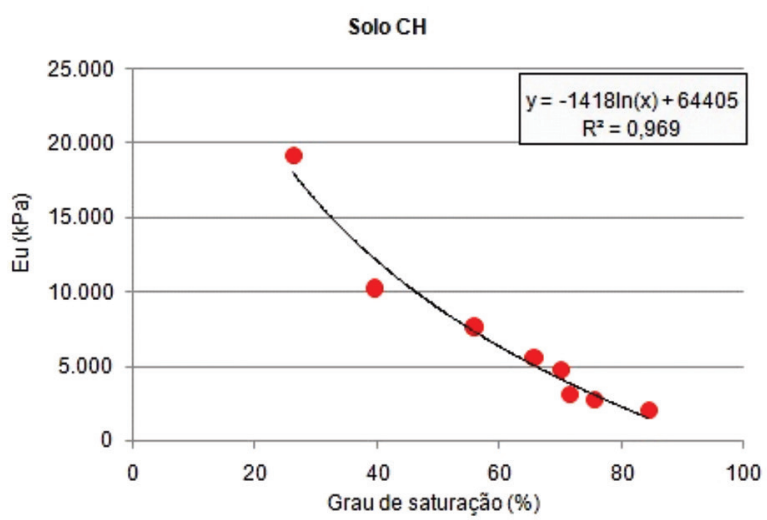

Figura 9. Relação não linear entre o módulo de elasticidade não drenado e o grau de saturação do solo $\mathrm{CH}$.

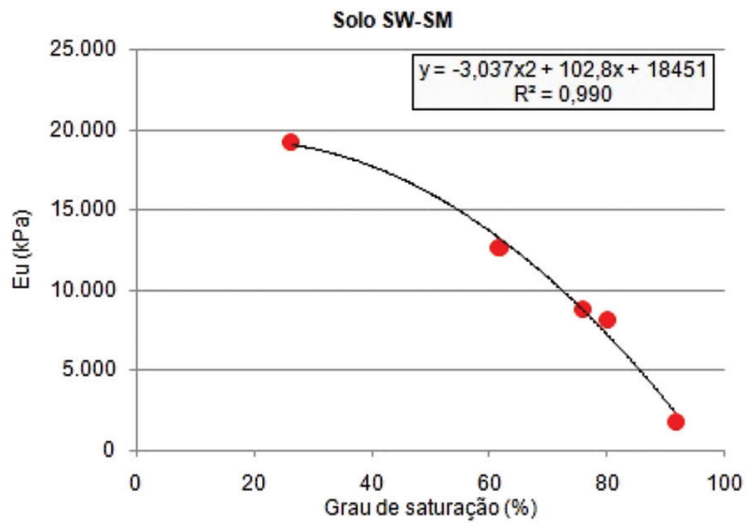

Figura 10. Relação não linear entre o módulo de elasticidade não drenado e o grau de saturação do solo SW-SM. saturação do solo foi comentada e discutida anteriormente. Como os valores do $v$ não foram determinados experimentalmente, vamos adotar os valores desse parâmetro tomando o artigo de Alramahi et al. (2010) como referência. Segundo os autores, para solos argilosos, como o $\mathrm{CH}$ desta pesquisa, o $v$ varia de $v 0,17$, para solo em condição seca, a 0,21 , para solo na condição úmida. Para solos com um maior teor de silte, como o SW-SM deste trabalho, $v=0,18$, uma vez que, segundo os autores, para esse tipo de solo o $v$ não varia tanto em função da umidade como ocorre nos solos argilosos.

Para o cálculo da rigidez no contato, além dos parâmetros elásticos do solo (indentado), é necessário conhecer os parâmetros elásticos das rochas (indentadores). Os módulos de elasticidade (E') e os coeficientes de Poisson ( $\left.v^{\prime}\right)$ foram obtidos dos trabalhos de Ribeiro (2013), para o hornblenda-biotita gnaisse, e de Castro (2016), para o gabro, conforme a Tabela 7.

Com base nos dados experimentais obtidos nesta pesquisa, apresentamos na Tabela 8 todos os dados de entrada e os valores calculados de $\mathrm{E}^{*}$.

Finalmente, a determinação da rigidez no contato do bloco de rocha (indentador) com a superfície do solo (indentada) é dependente também da área de contato entre o indentador e a superfície indentada: trata-se do parâmetro 'a' (área de contato) da Equação 3. Em casos reais, esse parâmetro pode ser determinado ou estimado observando-se as marcas de impacto na superfície do terreno (Paronuzzi, 2009). Vale ressaltar que esse tipo de dado não é tratado com frequência nos artigos que abordam essa tipologia de movimento de massa. Portanto, dados sobre as áreas de contato em função das características geológicas do bloco de rocha e do material geológico na superfície do talude são ainda escassos na literatura.

Com o intuito de analisar a rigidez no contato entre o solo e a rocha em função da umidade do solo no momento do impacto e considerando a já comentada escassez de dados sobre a área de contato, vamos adotar relações entre as áreas de contato com o solo no estado mais úmido e no estado mais seco $\left(a_{\text {imido }} / a_{\text {seco }}\right)$, variando entre 1,25 e 2,00. Ao se adotar essa variação para a área de contato $(a)$, a relação entre a rigidez normal no contato entre rocha e solo, considerando este no estado mais úmido $\left(k_{\text {umiddo }}\right)$ e no estado mais seco $\left(k_{\text {seco }}\right)$, varia aproximadamente entre 15 e $20 \%$, tanto para o solo CH quanto para o solo SW-SM. Há uma drástica redução da rigidez no contato quando os solos se aproximam da saturação. Esse fato mostra claramente que os alcances dos blocos de rocha nos processos de queda

Tabela 7. Valores do módulo de elasticidade e coeficiente de Poisson do hornblenda-biotita gnaisse (Ribeiro, 2013) e do gabro (Castro, 2016).

\begin{tabular}{lcc}
\hline Rocha & E' (GPa) & v' \\
\hline Hornblenda-biotita gnaisse & 32 & 0,24 \\
Gabro & 57 & 0,14 \\
\hline
\end{tabular}


Tabela 8. Dados experimentais de entrada e o cálculo de E*.

\begin{tabular}{|c|c|c|c|c|c|}
\hline \multicolumn{6}{|c|}{ Solo $\mathrm{CH}$ (hornblenda-biotita gnaisse). Condição mais seca $(\mathrm{S}=26,27 \%)$} \\
\hline \multicolumn{2}{|c|}{ Rocha } & \multicolumn{2}{|c|}{ Solo } & \multirow{2}{*}{$1 / E^{\star}$} & \multirow{2}{*}{$E^{*}$} \\
\hline$E^{\prime}(\mathrm{Pa})$ & $v^{\prime}$ & $\mathrm{E}_{\mathrm{u}}(\mathrm{Pa})$ & $v$ & & \\
\hline $3,20 \times 10^{10}$ & 0,24 & $1,92 \times 10^{7}$ & 0,17 & $5,07 \times 10^{-8}$ & $1,97 \times 10^{7}$ \\
\hline \multicolumn{6}{|c|}{ Solo CH (hornblenda-biotita gnaisse). Condição mais úmida ( $\mathrm{S}=84,37 \%$ ) } \\
\hline \multicolumn{2}{|c|}{ Rocha } & \multicolumn{2}{|c|}{ Solo } & \multirow{2}{*}{$1 / E^{*}$} & \multirow{2}{*}{$E^{*}$} \\
\hline$E^{\prime}(\mathrm{Pa})$ & $v^{\prime}$ & $\mathrm{E}_{\mathrm{u}}(\mathrm{Pa})$ & $v$ & & \\
\hline $3,20 \times 10^{10}$ & 0,24 & $2,06 \times 10^{6}$ & 0,21 & $4,64 \times 10^{-7}$ & $2,15 \times 10^{6}$ \\
\hline \multicolumn{6}{|c|}{ Solo SW-SM (Gabro). Condição mais seca (S = 26,38\%) } \\
\hline \multicolumn{2}{|c|}{ Rocha } & \multicolumn{2}{|c|}{ Solo } & \multirow{2}{*}{$1 / E^{*}$} & \multirow{2}{*}{$E^{*}$} \\
\hline$E^{\prime}(\mathrm{Pa})$ & $v^{\prime}$ & $\mathrm{E}_{\mathrm{u}}(\mathrm{Pa})$ & $v$ & & \\
\hline $5,70 \times 10^{10}$ & 0,14 & $1,91 \times 10^{7}$ & 0,18 & $5,06 \times 10^{-8}$ & $1,97 \times 10^{6}$ \\
\hline \multicolumn{6}{|c|}{ Solo SW-SM (Gabro). Condição mais úmida (S = 91,72\%) } \\
\hline \multicolumn{2}{|c|}{ Rocha } & \multicolumn{2}{|c|}{ Solo } & \multirow{2}{*}{$1 / E^{\star}$} & \multirow{2}{*}{$E^{*}$} \\
\hline$E^{\prime}(\mathrm{Pa})$ & $v^{\prime}$ & $E_{u}(P a)$ & $v$ & & \\
\hline $5,70 \times 10^{10}$ & 0,14 & $1,84 \times 10^{6}$ & 0,18 & $5,26 \times 10^{-7}$ & $1,90 \times 10^{6}$ \\
\hline
\end{tabular}

podem ser bem maiores se estes ocorrem em períodos de baixa umidade do solo.

\section{CONCLUSÕES}

Os dados obtidos nesta pesquisa mostram que a umidade dos solos nas encostas afeta fortemente os seus parâmetros elásticos em condições de carregamento instantâneo e não drenado, representativas dos choques em processos de queda de matacões e blocos de rocha. Como consequência, a rigidez no contato entre o bloco da rocha em queda e a superfície impactada do solo é acentuadamente reduzida em solos com umidade elevada, apresentando valores tão baixos quanto 15 a $20 \%$ dos valores de rigidez em solo com umidade reduzida, ainda que a procedência das rochas e dos solos derivados seja de natureza distinta.

Os resultados aqui apresentados implicam que as análises de risco associadas aos processos de queda e rolamento de blocos de rochas que envolvem a determinação da trajetória e do alcance devem levar em consideração a variação sazonal da umidade dos solos nas encostas, uma vez que esse tipo de processo pode ser disparado tanto em épocas secas quanto de elevada precipitação pluviométrica.

Tendo em vista que dados sobre a rigidez e o amortecimento de solos tropicais são escassos na literatura técnica, as elevadas variações da rigidez normal encontradas neste trabalho abrem um enorme campo de investigação sobre o tema. Dados dessa natureza serão de grande relevância para países de clima tropical e intemperismo químico dominante, onde encostas com afloramentos de rocha podem estar em contato com espessas exposições de solo residual.

\section{AGRADECIMENTOS}

Os autores agradecem aos dois revisores anônimos que muito contribuíram para melhorar a qualidade do artigo com as sugestões apresentadas e as discussões propostas. Ao Conselho Nacional de Desenvolvimento Científico e Tecnológico (CNPq), pela bolsa de mestrado da primeira autora e pela bolsa de doutorado do segundo autor. À Coordenação de Aperfeiçoamento de Pessoal de Nível Superior (CAPES), por alocar recursos para trabalhos de campo por meio do Programa de Apoio à Pós-Graduação (PROAP). À Fundação Carlos Chagas Filho de Amparo à Pesquisa do Estado do Rio de Janeiro (FAPERJ), pela bolsa do Programa Jovem Cientista do Nosso Estado (processo E-26/103.062/2012) concedida ao terceiro autor.

\section{REFERÊNCIAS}

Alramahi, B., Alshibli, K.A., Fratta, D. (2010) Effect of fine particle migration on the small-strain stiffness of insaturated soils. Journal of Geotechnical and Geoenvironmental Engineering, 136(4), 620-628.

Associação Brasileira de Normas Técnicas (ABNT). (1984a). Grãos de solos que passam na peneira de 4,8 $\mathrm{mm}$ : determinação da massa específica dos grãos. Método de ensaio (NBR 6508). Rio de Janeiro: ABNT.

Associação Brasileira de Normas Técnicas (ABNT). (1984b). Solo: análise granulométrica. Método de ensaio (NBR 7181). Rio de Janeiro: ABNT. 
Associação Brasileira de Normas Técnicas (ABNT). (1984c). Solo: determinação do limite de liquidez. Método de ensaio (NBR 6459). Rio de Janeiro: ABNT.

Associação Brasileira de Normas Técnicas (ABNT). (1984d). Solo: determinação do limite de plasticidade. Método de ensaio (NBR 7180). Rio de Janeiro: ABNT.

Associação Brasileira de Normas Técnicas (ABNT). (1986). Amostras de solo: preparação para ensaios de compactação e ensaios de caracterização. Método de ensaio (NBR 6457). Rio de Janeiro: ABNT.

Associação Brasileira de Normas Técnicas (ABNT). (1992). Rochas para revestimento: determinação da massa específica aparente, porosidade aparente e absorção d'água aparente. Método de Ensaio (NBR 12766). Rio de Janeiro: ABNT.

Associação Brasileira de Normas Técnicas (ABNT). (1995). NBR 6502. Solos e rochas. Terminologia. Rio de Janeiro: ABNT.

American Society for Testing and Materials (ASTM). (2003a). Standard test method for measurement of soil potential (suction) using filter paper (D 5298 - 03). Philadelphia: ASTM.

American Society for Testing and Materials (ASTM). (2003b). Standard test method for unconsolidated-undrained triaxial compression test on cohesive soils (D 2850 -03). Philadelphia: ASTM.

Azzoni, A., Freitas, M. H. (1995). Experimental gained parameters, decisive for rock fall analysis. Rock Mechanics and Rock Engineering, 28(2), 111-124.

Barbieri, G., Giani, G. P., Uras, G., Vernier, A. (1988). Modellizzazione della frana di crollo di Monte Oili in agro di Baunei (Nuoro). Riunione Plenaria delle Unita Operative del CNR. Roma: Consiglio Nazionale delle Ricerche.

Bernstein, A. D. (1977). Listening to the coefficient of restitution. American Journal of Physics, 45(41), 41-43.

Carnevale, G. (1991). Simulações Teóricas de Casos de Desmoronamento de Taludes Rochosos de Taludes Rochosos. Solos e Rochas, 14(1), 21-40.

Castro, A. S. (2016). Variação de rigidez normal no contato rocha e solo em função do grau de saturação. Dissertação (Mestrado). Rio de Janeiro: Departamento de Geologia, Instituto de Geociências - UFRJ.
Chau, K. T., Wong, R. H. C., Wu, J. J. (2002). Coefficient of restitution and rotational motions of rockfall impacts. International Journal of Rock Mechanics and Mining Sciences, 39(1), 69-77.

Cruden, D. M., Varnes, D. J. (1996). Landslide types and processes. In: A. K. Turner, R. L. Schuster (Eds.), Landslides: Investigation and Mitigation: Special Report 247. Washington, D.C.: Transportation Research Board, National Research Council. p. 36-75.

Dias, G. P., Barroso, E. V. (2006). Determinação experimental do coeficiente de restituição normal de rochas: aplicação na previsão do alcance de blocos em encostas. Anuário do Instituto de Geociencias, 29(2), 149-167.

Giani, G. P., Giacomini, A., Migliazza, M., Segalini, A. (2004). Experimental and theoretical studies to improve rock fall analysis and protection work design. Rock Mechanics and Rock Engineering, 37(5), 369-389.

Heidenreich, B. (2004). Small-and half-scale experimental studies of rockfall impacts on sandy slopes. Tese (Doutorado). Lausanne: Faculté Environnement Naturel, Architectural et Construit - Ecole Polytechnique Fédérale.

Hungr, O., Leroueil, S., Picarelli, L. (2014). The Varnes classification of landslide types: an update. Landslides, 11(2), 167-194.

Jackson, M. L. (1958). Soil chemical analysis. Nova Jersey: Prentice Hall Inc.

Lazaretti, A. F., Pinho, D., Silveira, M. C. M., Antonelli, T., Santos, L. F. (2015). Avaliação dos dados obtidos nas setorizações de risco realizadas no Espírito Santo. $X V$ Congresso Brasileiro de Geologia de Engenharia e Ambiental, CD-ROM, 11. Bento Gonçalves: ABGE.

Machado, M. L. M. R. (2013). Determinação do coeficiente de restituição de blocos de rochas em laboratório. Dissertação (Mestrado). Rio de Janeiro: Departamento de Geologia, Instituto de Geociências - UFRJ.

Paronuzzi, P. Rockfall-induced block propagation on a soil slope, northern Italy (2009). Environmental Geology, 58(7), 1451-1466.

Peng, B. (2000). Rockfall trajectory analysis: parameter determination and application. Tese (Mestrado em Ciências). Christchurch: Department of Geological Sciences - University of Canterbury. 
Polivanov, H. (1998). Caracterização química, mineralógica, física e geotécnica de perfiz de alteração desenvolvidos de gnaisses no Rio de Janeiro. Tese (Doutorado). Rio de Janeiro: Departamento de Geologia, Instituto de Geociências - UFRJ.

Pulecio, S. A. R. (2010). Modelamento do ensaio de indentação instrumentada usando elementos finitos e análise dimensional: análise de unicidade, variações experimentais, atrito e geometria e deformações do indentador. Tese (Doutorado). São Paulo: Escola Politécnica - USP.

Rayudu, D. N. P. (1997). Computer simulation of rockfalls: application to rockfalls at Fox Glacier, West Coast, New Zealand. Tese (Mestrado em Ciência). Christchurch: Department of Natural Resources Engineering - Lincoln University.

Ribeiro, R. S. (2013). Simulação do processo de queda de blocos em encostas com aplicação da mecânica do contato e do método dos elementos discretos. Tese (Doutorado). Rio de Janeiro: Departamento de Geologia, Instituto de Geociências - UFRJ.

Ribeiro, R. S., Barroso, E. V., Borges, A. F. (2008). Simulação do alcance de blocos rochosos em encosta urbana ocupada no município de Petrópolis (RJ). XII Congresso Brasileiro de Geologia de Engenharia e Ambiental, CD-ROM, 11. Porto de Galinhas: ABGE.

Ritchie, A. M. (1963). Evaluation of Rockfall and its Control. Highway Research Record, 17, 13-28.

Stevens, W. D. (1998). RocFall: a tool for probabilistic analysis, design of remedial measures and prediction of rockfalls. Tese (Mestrado em Ciência). Toronto: Department of Civil Engineering - University of Toronto.

Tupinambá, M. (1999). Evolução tectônica e magmática da Faixa Ribeira na região serrana do estado do Rio de Janeiro. Tese (Doutorado). São Paulo: Instituto de Geociências - USP.
Tupinambá, M., Heilbron, M., Oliveira, A., Pereira, A. J., Cunha, E. R. S. P., Fernandes G. A., Ferreira, F. N., Del Castilho, J. G., Teixeira, W. (1996). Complexo Rio Negro uma unidade estratigráfica relevante no entendimento da evolução da Faixa Ribeira. XXXIX Congresso Brasileiro de Geologia. Anais, 6, 104-107. Salvador: SBG.

Tupinambá, M., Gontijo, A., Silva, T. M., Dias, D. A., Menezes, P. T. L., Mane, M. A., Palermo, N., Mello, R. P., Silva, L. G. E., Motta, M., Almeida, C. G., Heilbron, M., Ferrassoli, M. A., Duarte, B. P., Almeida, J. C. H., Geraldes, M. C., Valladares, C., Conceição, F. R., Salomão, M. S., Benac, P. M., Mello, R. S., Pacheco, B. T., Silva, H. M. O. C., Guimarães, P. V., Silva, F. L. (2012). Geologia e recursos minerais da folha Nova Friburgo SF.23-Z-B-II, estado do Rio de Janeiro escala 1:100.000. Organizador: Luiz Carlos da Silva. Belo Horizonte: CPRM. CD-ROM. 136 p.

Vargas Jr., E. A., Castro, J. T., Amaral, C. P., Figueiredo, R. P. (2004). On mechanisms for failures of some rock slopes in Rio de Janeiro, Brazil: thermal fatigue? Ninth International Symposium on Landslides, n. 2, 1007-1011. Rio de Janeiro: A. A. Balkema Publishers.

Vargas Jr., E. A., Velloso, R. Q., Chávez, L. E., Gusmão, L. A., Amaral, C. P. (2013). On the effect of thermally induced stresses in failures of some rock slopes in Rio de Janeiro, Brazil. Rock Mechanics and Rock Engineering, 46(1), 123-134.

Varnes, D. J. (1978). Slope movement types and processes. In: R. L. Schuster, R. J. Krizek (Eds.), Landslides: Analysis and Control (v. 176, 11-33). Washington, D.C.: Transportation Research Board.

Yilmas, I., Yildirim, M., Keskin, I. (2008). A method for mapping the spatial distribution of RockFall computer program analyses results using ArcGIS software. Bulletin of Engineering Geology and the Environment, 67(4), 547-554. 